\title{
Expert committee classifier for hand motions recognition from EMG signals
}

\author{
Clasificador comité de expertos para el reconocimiento de movimientos \\ de la mano usando señales EMG
}

\author{
David A. Reyes López ${ }^{1 *} \quad$ Humberto Loaiza Correa ${ }^{2}$ \\ Mauricio Arias López ${ }^{3} \quad$ Jorge E. Duarte Sánchez ${ }^{4}$ \\ Recibido 7 de abril de 2016, aceptado 28 de noviembre de 2016 \\ Received: April 7, 2016 Accepted: November 28, 2016
}

\begin{abstract}
This paper presents the design and implementation of a novel technique for the recognition of four hand motions for real time response (flexion (FL), extension (EX), opening (OP) and closure (CL)) from electromyographic (EMG) signals generated from two forearm muscles: palmaris longus and extensor digitorum. The development of the work had two main stages: the low cost hardware for acquisition and conditioning of the EMG analog signals and the processing system for the identification and classification of the movement performed for real time response; the entire system was integrated in a hardware-software application using MATLAB and processing techniques for the discriminant analysis were performed. Three methods were evaluated for pattern recognition getting $98 \%$ recognition rates with the method proposed which had the best performance.
\end{abstract}

Keywords: Neural networks and support vector machines, EMG signals, discriminant function, real time response.

\section{RESUMEN}

Este trabajo presenta el diseño e implementación de una nueva técnica para el reconocimiento de cuatro movimientos de la mano (flexión $(F L)$, extensión $(E X)$, apertura $(O P)$ y cierre $(C L)$ ) para respuesta en tiempo real a partir de señales electromiográficas EMG generadas desde dos músculos del antebrazo: palmaris longus y extensor digitorum. El trabajo se desarrolló en dos principales etapas: el hardware de bajo costo para la adquisición y adecuación analógica de las señales EMG; el sistema de procesamiento para la identificación y clasificación de los movimientos capturados para respuesta en tiempo real. El sistema fue integrado mediante una aplicación hardware-software usando MATLAB y se usaron técnicas de procesamiento para el análisis discriminante. Tres métodos fueron evaluados para el reconocimiento de patrones obteniendo tasas de reconocimiento del $98 \%$ con el nuevo método propuesto.

Palabras clave: Redes neuronales y máquina de vectores de soporte, señales EMG, función discriminante, respuesta en tiempo real.

1 Grupo de Investigación Percepción y Sistemas Inteligentes. Escuela de Ingeniería Eléctrica y Electrónica. Universidad del Valle. Cali, Colombia. E-mail: david.reyes@ correounivalle.edu.co

2 Grupo de Investigación Percepción y Sistemas Inteligentes. Escuela de Ingeniería Eléctrica y Electrónica. Universidad del Valle. Cali, Colombia. E-mail: humberto.loaiza@ correounivalle.edu.co

3 Grupo de Investigación Bionanoelectrónica. Escuela de Ingeniería Eléctrica y Electrónica. Universidad del Valle. Cali, Colombia. E-mail: mauricio.arias.lopez@correounivalle.edu.co

4 Grupo de Investigación Bionanoelectrónica. Escuela de Ingeniería Eléctrica y Electrónica. Universidad del Valle. Cali, Colombia. E-mail: jorge.enrique.duarte@ correounivalle.edu.co

* Autor de correspondencia. E-mail: david.reyes@ correounivalle.edu.co 


\section{INTRODUCTION}

Human machine interfaces are based on the use of biopotentials as a control signal for external devices including intelligent prostheses, which can assist people who have lost their limbs whether is caused by car accidents, industrial accidents, diabetes or as evidenced in a study by the Colombia's Management for Comprehensive Action against Anti-personnel Mines [1] that in Colombia another cause of amputation is related to anti-personnel mines injuries. To address these challenges there are several commercial prosthetic devices, developed in other countries, such as Otto Bock hand [2], the i-Limb [3] or SmartHand [4] that allow these people to recreate some of the human hand movements [5].

Several research results show that the most commonly biopotential used to control this type of prosthethics devices are the electromyographic EMG signals, which record the electrical activity generated in muscle tissue, produced during contraction and relaxation of muscles $[6,7,8,9,10]$. These signals give an idea of the neuromuscular activity associated with a contraction, but does not necessarily indicates the force developed by the muscle, instead it gives the information of which muscle was activated by the central nervous system and which muscle provides indirectly a more leading role in a function or movement particularly [6]. EMG signals are used in the medical field for diagnosing muscle diseases such as myopathy, neuropathy [11] or Parkinson's disease [12] and, thanks to technological advances these signals are also used as control signals for electronic systems.

Today many studies address the treatment of EMG signals and are used in several fields, for example, assistive devices for disabled people [13] prosthetic hands $[14,15]$ or control signals for electric wheelchairs [16], however most works tends to be laborious and expensive equipment are used [17]. Some problems have been detected in the development of an EMG system:

A. Proper selection of muscles and the position of the electrodes to acquire the EMG signal.

B. Construction of a discriminant function.

In conventional systems, the greatest interest is to obtain a high recognition rate with $\mathrm{B}$. Many methods are used as discriminant functions to recognize EMG signals regardless of the subject. For better identification, it has had to choose the muscles that are activated directly by the movement [18].

The proposed system was developed in two stages of work, which were divided into phases; the first stage is divided into three phases: analog acquisition-conditioning, transmission and analog to digital conversion of EMG signals. The second stage is the design of the discriminant function in software using processing and pattern recognition techniques, which main objective was to identify the movement made from the EMG signals captured. Figure 1 shows the diagram block implemented for the development of the myoelectric integral system.

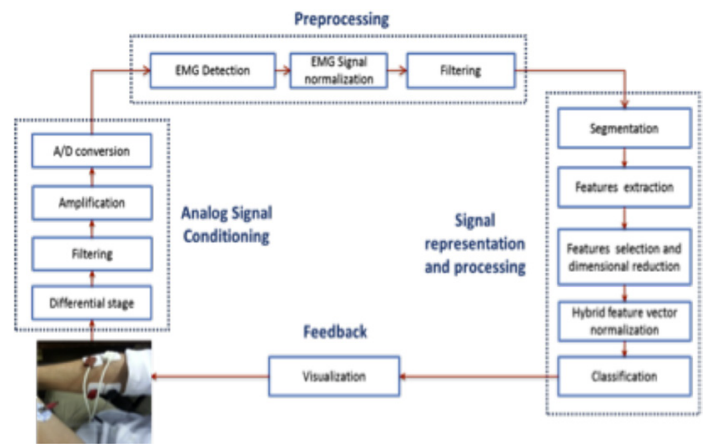

Figure 1. Diagram block of the process implemented in the development of this work.

\section{ANALOG EMG SIGNAL ACQUISITION AND CONDITIONING}

As in [19] this work implemented a low cost two channel hardware system to acquire EMG signals superficially, so the signal acquisition can be performed with minimal risk to the patient [20]. The signal captured by the electrodes is connected to an analog and conditioning block which amplifies and filters the signal. For the Analog to Digital (AD) conversion computer's stereo sound card was configured so the EMG analog signals was conditioned to the voltage range that the card allows.

\section{A. EMG signal acquisition}

In works such as [21,22] and [23] forearm muscles were used to capture hand movements producing enough useful information for the task, according 
to that extensor digitorum and palmarus longus muscles were selected in this work. The selected muscles are extensors and flexors muscles of the wrist joint having antagonistic participation in some hand movements [24]. For each muscle two cardiography monopolar electrodes were used. The location of the electrodes is of great significance because locating them wrong could cause unwished results in the system. Electrodes are properly placed to acquire the EMG signals in this work as shown in Figure 2, reference electrode were positioned on the opposite forearm.

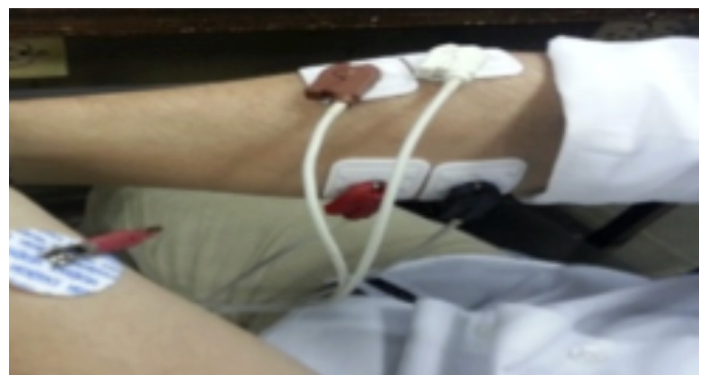

Figure 2. Electrodes properly placed to acquire the EMG signals in this work.

\section{B. Analog EMG signal conditioning}

For the conditioning of the analog EMG signal it was designed and implemented an analog circuit described by the characteristics in Table 1 . Is worth mentioning that in a similar manner in works such as $[25,26,27,28]$, the interference of $60 \mathrm{~Hz}$ was not filtered due it is within the useful frequency range of the EMG signals.

Table 1. Parameters for analog conditioning of the EMG signal.

\begin{tabular}{|l|l|}
\hline \multicolumn{2}{|c|}{ EMG signal adequacy } \\
\hline \multicolumn{1}{|c|}{ Stage } & \multicolumn{1}{c|}{ Description } \\
\hline Acquisition & Two channel \\
\hline Differential & $\begin{array}{l}\text { Instrumentation amplifiers } \\
\text { fixed gain: 1000 }\end{array}$ \\
\hline \multirow{2}{*}{ Filtering } & $\begin{array}{l}\text { 2nd order lowpass } \\
\text { butterworth filter } \\
\text { Fc }=600 \mathrm{~Hz}\end{array}$ \\
\hline Amplification & Adjustable gain $=2$ \\
\hline Circuit powersupply & 9V battery \\
\hline
\end{tabular}

Once the stage of the conditioning of analog EMG signal, movements are captured and viewed on an oscilloscope to test the operation of the analog system.

\section{EMG SIGNAL PROCESSING}

For the development of the processing system a computer application was designed using the experimental platform MATLAB under educational license. The laptop computer was a DELL Latitude with an Intel i5 @2.67 GHz processor and 2 GB Ram. Once the EMG signal is captured by the designed hardware it proceeds to perform a pre-processing stage that consists of several sub-stages:

\section{A. Analog to digital conversion}

To convert the EMG signal from analog to digital the sound card stereo input of the computer was configured using the minimum sampling frequency $(8 \mathrm{kHz})$, much higher than the bandwidth of interest $(500 \mathrm{~Hz})$. Data Acquisition Toolbox was used to gather data. In Figure 3 a captured EMG signal with the hardware implemented and converted into digital is shown.

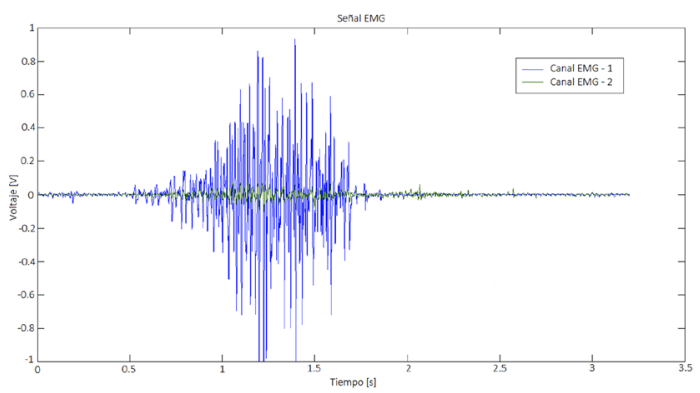

Figure 3. Two channel EMG signal gathered in MATLAB with the hardware designed (Blue: Extensor digitorum muscle - Green: Palmaris longus muscle).

\section{B. Preprocessing stage}

Processing techniques were implemented such as: Resampling, filtering, EMG signal detection, segmentation and normalization. Table 2 shows the parameters of this stage.

For the EMG signal detection several threshold values were evaluated because in the literature a fixed value is not specified for this. In [29] mention that using a single threshold value for different intensities of exercises or different muscle groups can cause misleading results. Thus, researchers may need to use different strategies to establish a threshold value. As a result, they not recommend any defined threshold value due to the highly variable nature of the selection process. In this work the 
Table 2. Parameters for the preprocessing stage.

\begin{tabular}{|l|l|}
\hline \multicolumn{2}{|c|}{ Digital emg signal Pre-processing } \\
\hline \multicolumn{1}{|c|}{ Stage } & \multicolumn{1}{c|}{ Description } \\
\hline Resample & $8 \mathrm{kHz}$ to $1 \mathrm{kHz}$ \\
\hline Filtering & $\begin{array}{l}160 \text { order bandpass fir } \\
\text { filter fc }=[20-600] \mathrm{Hz}\end{array}$ \\
\hline EMG signal normalization & $\begin{array}{l}\text { EMG signal } \\
\text { maximum detection }\end{array}$ \\
\hline EMG signal detection & $\begin{array}{l}\text { Threshold detection }= \\
400 \text { mV }\end{array}$ \\
\hline Segmentation & $\begin{array}{l}256 \text { samples of each } \\
\text { emg signal }\end{array}$ \\
\hline
\end{tabular}

best performing threshold for detection of EMG signals was $400 \mathrm{mV}$.

For the analysis of EMG signals, the most common is to obtain the records into segments of length 256 samples and apply the techniques of feature extraction for each segment [29]. Meanwhile, [23] and [30] use the length of segments 256, 128, 64 and 32 samples in each assay and, as in other works [31], use of rectangular windows 200 and $400 \mathrm{~ms}$ with results equally satisfactory but with the notation that greater lengths imply more processing time and greater delay in the response. In this case segmentation of 256 samples was done.

\section{Gathering the EMG Data}

Through voluntary participation, 11 subjects, men and women without disabilities between 11 and 60 years old were selected. A protocol for acquiring movements to classify, wrist extension, wrist flexion, opening and closing the hand, as shown on Figure 4, was done consisting in performing 10 repetitions of each movement in periods of $2 \mathrm{~s}$, obtaining thus a total of 110 samples per movement. To avoid fatigue as in [23] subjects were allowed to rest for 1-5 min. The parameters to make the dataset were the same as described previously. To have information of steady and transient states, the EMG signal was gathered for the entire movement, from the beginning of it til the reach of rest state.

\section{Features extraction and dimensional reduction}

With the dataset of the EMG signal obtained, to identify the movements made, several computational techniques processing were performed. In [5] mention works that have used several methods in both time
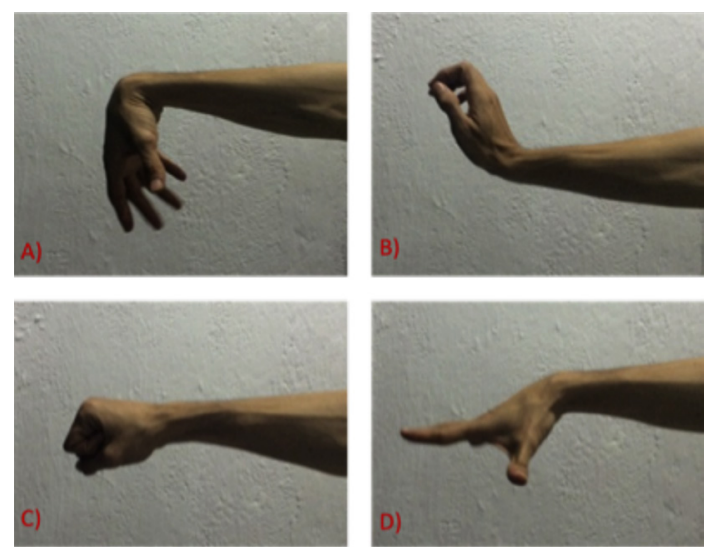

Figure 4. Motions performed in the system. A) Hand or wrist flexion. B) Hand or wrist extension. C) Hand closure. D) Hand opening.

and frequency domain getting good results in the EMG pattern recognition. In this paper statistical analysis methods such as mean, variance, energy, maximum value and relations between features were used in the time and frequency processing techniques for each channel or muscle. The Fast Fourier Transform (FFT) was implemented to obtain the signal in the frequency domain. A total of 34 variables were calculated as described in Table 3.

Due to the large number of variables calculated, the resulting features vector is large which reflects in a very high computational cost if it is used as inputs for the recognition system. Two techniques for the analysis and feature extractions were applied to address the problem and achieve a reduction in the dimensionality of the vector: Covariance matrix (MC) between features were performed and Principal Component Analysis (PCA) which in [5] had good performance in the results obtained. Figure 5 shows the results of the covariance matrices calculated in (a) for the 4 movements to classify, in (b) for two movements (flexion and extension of the wrist) and (c) for both remaining motions (opening and closing the hand). The matrix have a tendency in colors scales where green means that the covariance between features are small or close to 0 , the red colors are those whose covariance are close to 1 . Comparisons with the features with covariances close to 0 and covariances close to 1 were performed, as shown in Figure 5 there are several features with covariances tending to 1 , which gives information 
Table 3. Extracted features in EMG signals.

\begin{tabular}{|l|c|l|c|}
\hline \multicolumn{1}{|c|}{ Temporal space } & Number of variables & \multicolumn{1}{c|}{ Frequency space (FFT) } & Number of variables \\
\hline Mean per muscle & 2 & Mean per muscle & 2 \\
\hline Var per muscle & 2 & Var per muscle & 2 \\
\hline Energy per muscle & 2 & Maximun per muscle & 2 \\
\hline Maximum per muscle & 2 & Frequency of maximum per muscle & 2 \\
\hline Mean Difference & 1 & Mean Difference & 1 \\
\hline Var Difference & 1 & Var Difference & 1 \\
\hline Energy Difference & 1 & Maximum difference & 1 \\
\hline Maximum difference & 1 & Mean Division & 1 \\
\hline Mean Division & 1 & Var Division & 1 \\
\hline Var Division & 1 & Maximum Division & 2 \\
\hline Energy Division & 1 & Var $\div$ Mean; & 2 \\
\hline Maximum Division & 1 & Maximum $\div$ Mean difference & 18 \\
\hline Total & 16 & & \\
\hline
\end{tabular}

of dependency between features. After the MC analysis a PCA were done to the features with best performance in the discriminant issue obtaining that with the first 4 principal components it can get up to $94.5 \%$ variance of the total data.

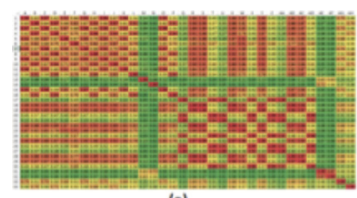

(a)

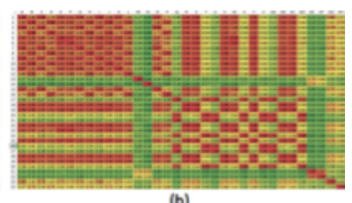

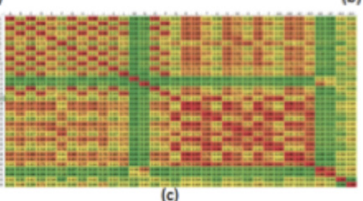

Figure 5. Covariance matrices calculated in the features extraction process.

After a series of evaluations, finally features which performed the best on the discrimination of movements captured by the EMG system, were selected. Table 4 shows the features that were implemented as an entry for the classification system.

Table 4. Features selected after the dimension reduction stage.

\begin{tabular}{|l|}
\hline \multicolumn{1}{|c|}{ Feature } \\
\hline Var FFT - Channel 2 \\
\hline Energy - Channel 1 \\
\hline Maximum FFT - Channel 2 \\
\hline Mean FFT - Channel 1 \\
\hline
\end{tabular}

Figure 6 shows the representation of the four movements in a $2 \mathrm{D}$ view for display purposes. The influences of selected muscles that have antagonistic activity to identify movements, such as extension and flexion of the hand, have a clear discrimination between them. On the other hand, it also noted that for the movements that have synergistic activity, as opening and closing the hand, one muscle group participates more actively than the other, that is, to close the hand, contributes more to the movement the flexor muscles than the extensor ones and in an opposite case with hand opening.

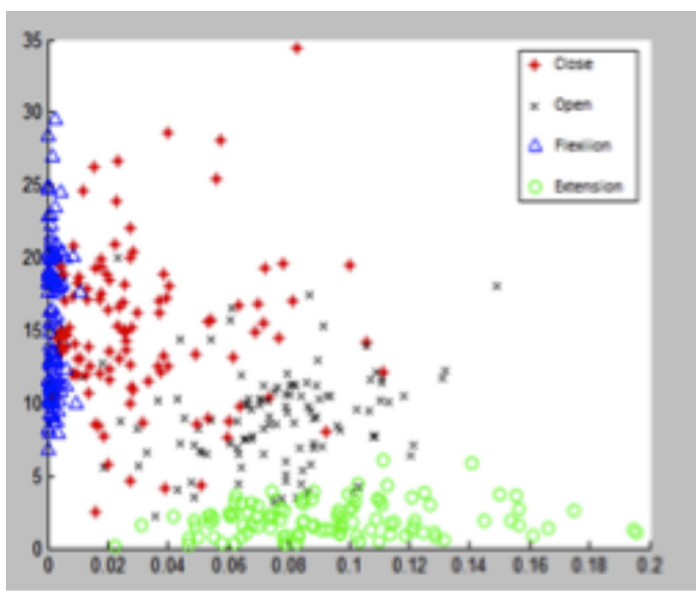

Figure 6. 2D view of the four motions to classify.

\section{E. Identification of the motions from EMG signals}

For the identification phase computational techniques were implemented for pattern classification, dividing the dataset by $50 \%$ for training and $50 \%$ for validation 
and testing. Three classification techniques were implemented for the recognition of motions from the EMG signals captured. The first technique was implemented with a feedfordward artificial neural network (ANN) Multilayer Perceptron (MLP) type with 4 classes in its output, each corresponding to each movement. The second, a neural network with Radial Basis Function (RBF) also with 4 classes in its output layer. The results were satisfactory for both networks with different types of architectures in the training stage with a success averaged of $90 \%$. Table 5 shows the confusion matrix for both classifiers.

Table 5. A) Confusion Matrix for the MLP ANN trained. B) Confusion Matrix for the RBF ANN trained.

\begin{tabular}{|l|c|c|c|c|c|c|c|c|c|}
\cline { 4 - 10 } \multicolumn{1}{l|}{} & CL & EX & FL & OP & \multirow{2}{*}{ B) } & CL & EX & FL & OP \\
\hline CL & 66 & 1 & 3 & 11 & CL & 76 & 1 & 11 & 12 \\
\hline EX & 1 & 71 & 0 & 4 & EX & 1 & 95 & 0 & 4 \\
\hline FL & 3 & 0 & 79 & 1 & FL & 3 & 0 & 97 & 0 \\
\hline OP & 8 & 3 & 0 & 69 & OP & 13 & 8 & 0 & 79 \\
\hline
\end{tabular}

After analyzing the results obtained with the implemented classifiers it is proposed to improve the rate of classification because good results were obtained with the relevant classes, flexion and extension movements, but between opening and closing low recognition rate was evident.

The proposal was implemented by dividing the problem into three categories consisting to unify, into a single class, the opening and closing movements of the hand and together with the remaining 2 classes (flexion and extension) to implement an Expert Committee (EC). This EC is composed with two classifiers: one that discriminates the new unified class from the other two, and the second, a robust one, that allows the discrimination between the patterns with low recognition. For this, the first classifier a feedfordward MLP neural network was trained, this time with 3 classes at its output and the second classifier, the 'expert', by implementing Support Vector Machines (SVM) which had good performance in several works [9, 31, 32, 33] for the discrimination between two classes. Different SVM kernel functions were evaluated, obtaining a better performance for the linear function. An improvement was obtained in the recognition rate for the movements with greater confusion (opening and closing). Table 6 shows the results in the training stage for the EC proposal implemented to improve classification rates.

Table 6. Confusion Matrix for the EC proposal implemented. A) The MLP feedfordward ANN Confusion Matrix. B) SVM Confusion Matrix.

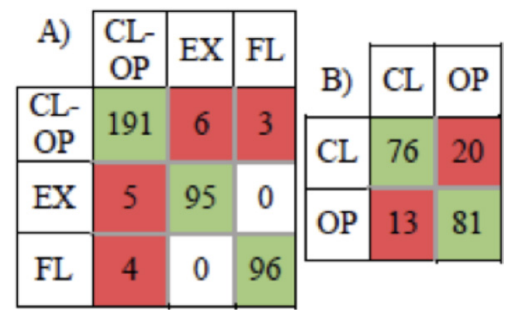

\section{VALIDATION AND TESTS RESULTS}

Testing was conducted for real time response of the myoelectric implemented system with 7 subjects without disabilities, men and women in the range between 20-40 years old, who voluntarily participated in the exercise. Needless to say, these people were not part of the data collected in the dataset obtained for the training phase of the classifiers. Tests were done for both forearms (right and left). Each subject received an introduction of the methodology to follow for using the EMG application, which was:

- Palpation of muscles selected for the correct electrode positioning.

- Preparation of the forearm muscles with conductivity gel.

- A mimic response for the motion to made which had a duration time of $1 \mathrm{~s}$.

- A visualization of the motion made was done using a Graphical User Interface (GUI) which gives the user an incentive when the system recognized a motion.

After obtaining the outputs of the classifiers a threshold called threshold decision is evaluated to get more accuracy in the classification results. A new class is introduced into the test parameters called "No Classify (NC)", which is activated when none output of the classifier exceeds the threshold decision. Several values of threshold decision were evaluated for each classification 
technique selecting the one with best performance in the recognition task.

Figure 7 shows how the variation of the threshold decision affects the success of class recognition.

A)

4 motions classification (MLP ANN) vs. threshold decision

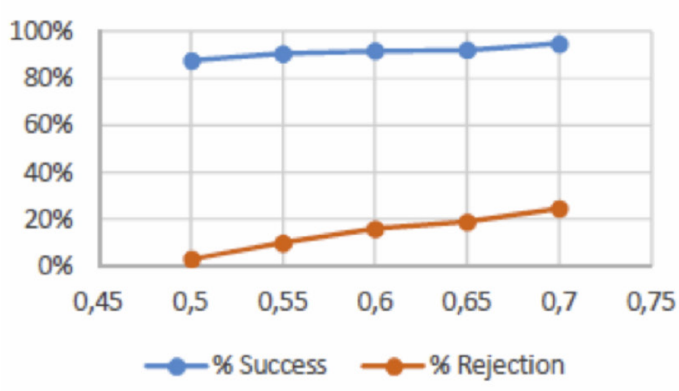

B)

4 motions classification (RBF ANN) vs. threshold decision

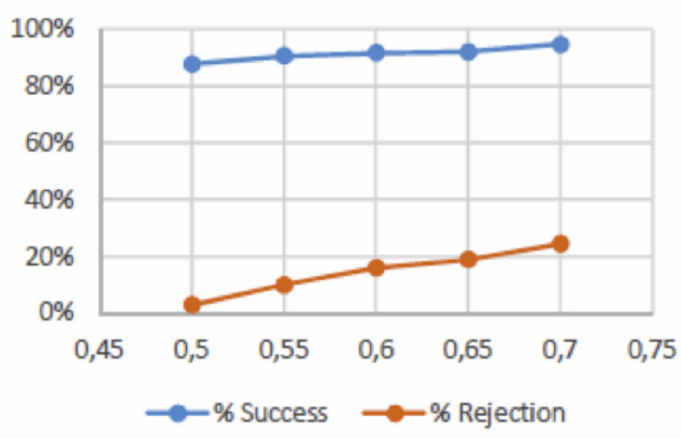

C)

Experts committee classification vs. threshold decision

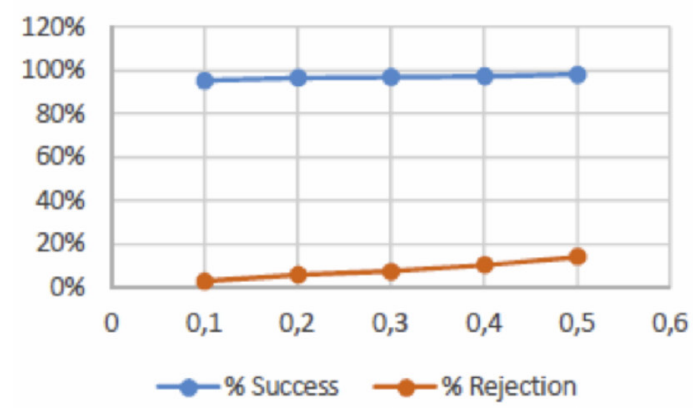

Figure 7. Threshold decision variation for each classification technique. A) MLP ANN B) RBF ANN C) Experts Committee.

After selecting the threshold with best performance, each technique was tested where it showed that the recognition rate increased for each evaluated method as shown in the tests confusion matrices.

Table 7. Test results. A) feedforward MLP ANN. B) RBF ANN. C) Expert Committee ANN+SVM.

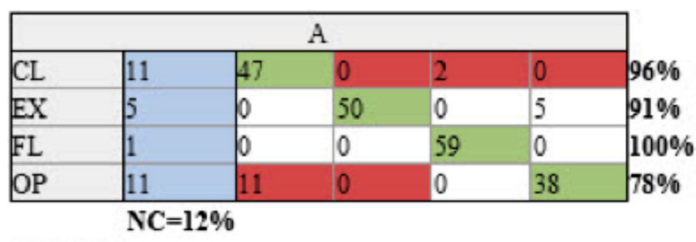

\section{Threshold}

decision: $\quad$ \% Success: $92 \%$

0.65

\begin{tabular}{|c|c|c|c|c|c|c|}
\hline & & & tion & & $12 \%$ & \\
\hline & & & & & & \\
\hline $\mathrm{CL}$ & 9 & 35 & 0 & 5 & 1 & $85 \%$ \\
\hline EX & 6 & 0 & 44 & 0 & 0 & $100 \%$ \\
\hline FL & 0 & 0 & 0 & 50 & 0 & $100 \%$ \\
\hline OP & 5 & 11 & 0 & 0 & 34 & $76 \%$ \\
\hline
\end{tabular}

\section{Threshold}

decision: $\quad$ \% Success: $\quad 91 \%$

0.55

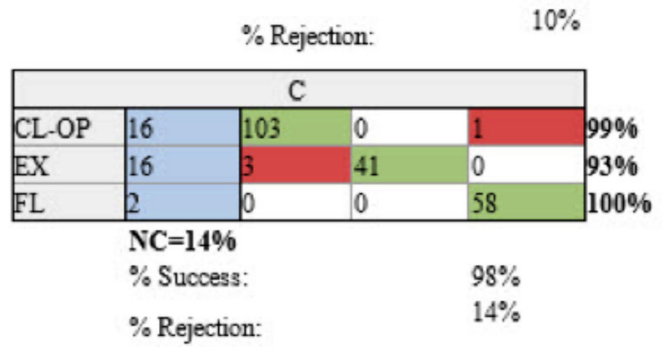

\begin{tabular}{|c|c|c|c|}
\hline \multirow{2}{*}{ SVM } & $\mathrm{CL}$ & 42 & 2 \\
\hline & OP & 5 & 53 \\
\hline
\end{tabular}

\section{Threshold decision: 0.5}

\section{DISCUSSION AND CONCLUSIONS}

It was designed and implemented a system that captures the EMG signals from forearm muscles for real-time identification of 4 hand movements (flexion, extension, opening and closing of the hand) comparing 3 types of classification techniques in the identification stage and getting results $>91 \%$ in the recognition rate for each classifier implemented and improving the rate to $98 \%$ with the implementation of a novel Expert Committee type Classifier. 
It is shown an improvement on classification results performed for real time response after dividing the problem of classification by implementing the new technique, Expert Committee and by evaluating the threshold decision for each of the classification techniques implemented. It was also observed that the "No Classify" class helps to improve the recognition rates.

The location of the electrodes is an important factor for the proper functioning of the system during the entire process (from training to testing), because if you mistakenly make it, the results produced by the system may not be as expected. It is therefore recommended to train movements to identify with people who will test the system even with the people who will be part of the dataset for the training phase, thus achieving improved recognition rate.

\section{FUTURE WORK}

In order to assess a muscle-computer interface, besides the generalization tests for the classifiers, a Controllability Test can be conducted as well (Target Achievement Control Test, [34]). So it can evaluate the performance of the system for kinetic and intrinsic geometric parameters in processes of prosthesis control by biosignals, such as EMG signals.

Although the system is trained and tested with forearm muscles in future works it can also have the same results capturing movements from other muscle groups, with the same characteristic of flexors and extensors, for example: biceps and triceps. This is because the movements identified in this work have an antagonistic participation.

\section{REFERENCES}

[1] "Dirección para la Acción Integral contra Minas Antipersonal". [Online]. Available: http://www.accioncontraminas.gov.co/ Paginas/aicma.aspx. Accessed: 20-May-2016. "Otto Bock Michelangelo - HealthCare". [Online]. Available: http://www.living-withmichelangelo.com/fileadmin/downloads/ techniker/english/technician_product_ brochure.pdf. Accessed: 20-May-2015.

[3] "i-Limb ultra revolution I Touch Bionics". [Online]. Available: http://www.touchbionics. com/products/i-limb-ultra-revolution. Accessed: 20-May-2015.

[4] C. Cipriani, M. Controzzi, and M. C. Carrozza. "The SmartHand transradial prosthesis". J. Neuroeng. Rehabil. Vol. 8 No 1, pp. 29. January, 2011.

[5] D. Zhang, X. Zhao, J. Han and Y. Zhao. "A comparative study on PCA and LDA based EMG pattern recognition for anthropomorphic robotic hand". In 2014 IEEE International Conference on Robotics and Automation (ICRA), pp. 4850-4855. 2014.

[6] D. Farina, N. Jiang, H. Rehbaum, A. Holobar, B. Graimann, H. Dietl and O. C. Aszmann. "The extraction of neural information from the surface EMG for the control of upper-limb prostheses: Emerging avenues and challenges". IEEE Trans. Neural Syst. Rehabil. Eng. Vol. 22 No 4, pp. 797-809. 2014.

[7] D. Farina and A. Holobar. "Humanmachine interfacing by decoding the surface electromyogram". IEEE Signal Process. Mag. Vol. 32, pp. 115-120. January, 2015.

[8] J.M. Azorín, R. Ceres, A. Frizera and T. Freire. "La Interacción de Personas con Discapacidad con el Computador: Experiencias y Posibilidades en Iberoamérica". 2013.

[9] A. H. Al-Timemy, G. Bugmann, J. Escudero and N. Outram. "Classification of finger movements for the dexterous hand prosthesis control with surface electromyography". IEEE J. Biomed. Heal. Informatics. Vol. 17 $\mathrm{N}^{\circ}$ 3, pp. 608-618. 2013.

[10] C. Cipriani, C. Antfolk, M. Controzzi, G. Lundborg, B. Rosen, M.C. Carrozza and F. Sebelius. "Online myoelectric control of a dexterous hand prosthesis by transradial amputees". IEEE Trans. Neural Syst. Rehabil. Eng. Vol. $19 \mathrm{~N}^{\circ} 3$, pp. 260-270. 2011.

[11] O.A. Alim, M. Moselhy and F. Mroueh. "EMG signal processing and diagnostic of muscle diseases". 2012 2nd Int. Conf. Adv. Comput. Tools Eng. Appl. ACTEA 2012, pp. 1-6. 2012.

[12] V. Ruonala, E. Pekkonen, S. Rissanen, O. Airaksinen, G. Miroshnichenko, M. Kankaanpää and P. Karjalainen. "Dynamic Tension EMG to Characterize the Effects of DBS Treatment of Advanced Parkinson's Disease", pp. 3248-3251. 2014. 
[13] K. Nagata, K. Ando, K. Magatani, and M. Yamada, "Development of the hand motion recognition system based on surface EMG using suitable measurement channels for pattern recognition". Annu. Int. Conf. IEEE Eng. Med. Biol. - Proc., p. 5214. 2007.

[14] O. Fukuda, T. Tsuji, M. Kaneko and A. Otsuka. "A Human-Assisting Manipulator Teleoperated by EMG Signals and Arm Motions". IEEE Trans. Robot. Autom. Vol. 19 $\mathrm{N}^{\circ}$ 2, pp. 210-222. 2013.

[15] A. Altamirano-Altamirano, G.A. ValentinoOrozco, A. Vera-Hernandez and L. Leija-Salas. "Hand prosthesis with 5 DOF using embedded systems". In 2013 Pan American Health Care Exchanges (PAHCE), pp. 1-6. 2013.

[16] R. Mahendran. "EMG signal based control of an intelligent wheelchair". In 2014 International Conference on Communication and Signal Processing, pp. 1267-1272. 2014.

[17] X. Li, J. Liu, S. Li and Y. Wang. "Examination of Hand Muscle Activation and Motor Unit Indices Derived from Surface EMG in Chronic Stroke". IEEE Trans. Biomed. Eng. Vol. 61 $\mathrm{N}^{\circ}$ 12, pp. 2891-2898. 2014.

[18] K. Nagata, K. Adno, K. Magatani and M. Yamada. "A classification method of hand movements using multi channel electrode". Conf. Proc. IEEE Eng. Med. Biol. Soc. Vol. 3 , pp. 2375-2378. 2005.

[19] D.A. Reyes López, M. Arias López, J.E. Duarte Sánchez and H. Loaiza Correa. "Implementación en FPGA de un clasificador de movimientos de la mano usando señales EMG”. Redes Ing. Vol. 6 No 1, pp. 85-94. 2015.

[20] J. Jairo and V. Mayor. "Detección de la intención de movimiento durante la marcha a partir de señales Electromiográficas". Tesis de Grado. Universidad del Valle, Ingeniería Electrónica. 2007.

[21] D. Reyes López, C. Cifuentes López and H. Loaiza Correa. "Design of an electromyographic mouse". In IEEE Conference proceedings: Signal Processing, Images and Computer Vision (STSIVA), 2015 20th Symposium on, pp. 1-8. 2015.

[22] G. Li, A. E. Schultz and T. a. Kuiken. "Quantifying pattern recognition- based myoelectric control of multifunctional transradial prostheses". IEEE Trans. Neural
Syst. Rehabil. Eng. Vol. $18 \mathrm{~N}^{\circ} 2$, pp. 185192. 2010.

[23] R.D. Pinzón Morales, D.A. Morales and V.H. Grisales. "Caracterización de señales Electromiográficas para la Discriminación De Seis Movimientos De La Mano". Scientia et Technica Año XV. No 42, pp. 278-283. Universidad Tecnológica de Pereira. 2009.

[24] N. Palastanga, D. Field and R. Soames. "Anatomy and human movement: structure and function". 6th Edition. Churchill Livingstone, Elsevier. 2006.

[25] A.H. Al-Timemy, G. Bugmann, J. Escudero and N. Outram. "Classification of finger movements for the dexterous hand prosthesis control with surface electromyography". IEEE J. Biomed. Heal. Informatics. Vol. 17 $\mathrm{N}^{\mathrm{o}}$ c, pp. 608-618. 2013.

[26] F. Rodríguez and M. Chavez. "Instrumentación Electrónica de un Exoesqueleto para Rehabilitación Asistida de Rodilla”. Universidad del Valle. 2010.

[27] H. a Romo, J.C. Realpe, P.E. Jojoa and U. Cauca. "Análisis de Señales EMG Superficiales y su Aplicación en Control de Prótesis de Mano Surface EMG Signals Analysis and Its Applications in Hand Prosthesis Control". Av. en Sist. e Informática. Vol. 4, pp. 127-136. 2007.

[28] K.T. Özgünen, U. Çelik and S.S. Kurdak. "Determination of an optimal threshold value for muscle activity detection in EMG analysis". J. Sport. Sci. Med. Vol. 9, pp. 620628. September, 2010.

[29] L.J. Hargrove, K. Englehart and B. Hudgins. "A comparison of surface and intramuscular myoelectric signal classification". IEEE Trans. Biomed. Eng. Vol. 54 NN$^{\circ}$ 5, pp. 847853. 2007.

[30] K. Englehart, B. Hudgins, P. Parker and M. Stevenson. "Time-requency representation for classification of the transientmyoelectric signal". Proc. 20th Annual. Int. Conf. IEEE Eng. Med. Biol. Soc. Vol. 20 Biomed. Eng. Towar. Year 2000 and Beyond (Cat. $\mathrm{N}^{\circ}$ 98CH36286). Vol. 5. 1998.

[31] G. Betancourt O., E. Giraldo Suárez and J.F. Franco B. "Reconocimiento de patrones de movimiento a partir de señales electromiográficas". Sci. Tech. $\mathrm{N}^{\mathrm{o}} 26$, pp. 53-58. 2004. 
[32] M. Leon and J. Gutierrez. "EMG pattern recognition using Support Vector Machines classifier for myoelectric control purposes". Health Care Exchanges (PAHCE), pp. 175178. 2011.

[33] P. Geethanjali and K.K. Ray. "A Low-Cost Real-Time Research Platform for EMG Pattern Recognition-Based Prosthetic Hand".
IEEE/ASME Trans. Mechatronics. Vol. 20 $\mathrm{N}^{\circ}$ 4, pp. 1-8, 2014.

[34] A.M. Simon, L.J. Hargrove, B.A. Lock and T.A. Kuiken. "Target Achievement Control Test: evaluating real-time myoelectric pattern-recognition control of multifunctional upper-limb prostheses". J. Rehabil. Res. Dev. Vol. $48 \mathrm{~N}^{\circ}$ 6, pp. 619-27. 2011. 